\title{
Analysis of vibration characteristics of inverter cabinet
}

\author{
Peng Jiang ${ }^{1, a, *}$, Yong Wu ${ }^{1, b}$, Qijun Pan ${ }^{2, ~ c}$, Fuli Ning ${ }^{3, d}$ and Guilin Chen ${ }^{1, e}$ \\ 1. School of Automation, Wuhan University of Technology, Wuhan 430070, China. \\ 2. Daqo Group Co. Ltd, Yangzhong 212211, China. \\ 3. Wuhan Enshuo Technology Co.Ltd, Wuhan 430062, China. \\ *,a1650548490@qq.com, bwuyong@whut.edu.cn, cpqijun@163.com, dnfl@aonesoft.com.cn, \\ e1559972750@qq.com
}

\begin{abstract}
Based on the theory of finite element dynamics, the dynamic performance of the power regulator inverter is studied in this paper. The vibration simulation model of the inverter is established. According to the national standard for vibration environment, the vibration load is applied to the model, and the vibration response characteristics of the cabinet under excitation are obtained. In this paper, through studying the simplification of the inverter model and the finite element mesh division, a good finite element mesh model of inverter is generated. And then the natural frequencies and modes of the inverter are obtained based on modal analysis. Finally, the frequency response range of inverter cabinet from the $0 \sim 120 \mathrm{~Hz}$ excitation of displacement and stress response are gotten through harmonic response analysis. Through vibration simulation analysis, the maximum impact on the structure in the frequency range of inverter can be found, and can be matched with modal analysis results.
\end{abstract}

Keywords: Finite element dynamic analysis, vibration load, modal analysis, harmonic response analysis.

\section{Introduction}

The cabinet is the equipment installation frame, when the power electronic equipment is subjected to the huge vibration, the cabinet may protect the equipment effectively not to be damaged, the structure design through the simulation method to the equipment strength analysis demand more and more.[1] Firstly, the mechanical model of the main frame of inverter cabinet is analyzed, and the structure is divided into grid. The vibration calculation is carried out along the $\mathrm{X}, \mathrm{Y}$ and $\mathrm{z}$ three axes, the modal analysis is carried out by the ANSYS software, the natural frequencies and the natural modes of the system are calculated, and then the natural frequencies and the natural modes which have the most influence on the system are found through the harmonic response analysis.

\section{Basic Theory of Finite Element Analysis}

General dynamics differential equation of finite element analysis is

$$
[M]\left\{\mathrm{u}^{\prime \prime}\right\}+[C]\left\{\mathrm{u}^{\prime}\right\}+[K]\{\mathrm{u}\}=\{\mathrm{F}(\mathrm{t})\}
$$

Where $[M]$ is structure quality matrix, $[C]$ is structural damping matrix, $[K]$ is structural stiffness matrix and $\mathrm{F}(\mathrm{t})$ is load function with time variation. $\mathrm{u}, \dot{u}$ and $\ddot{u}$ are nodal displacement vector, node velocity vector, and node acceleration vector respectively.

When the system is a free vibration system, the load function $F(t)=0$, so the dynamics equation (1) can be changed to:

Its characteristic equation is:

$$
[M]\left\{\mathrm{u}^{\prime \prime}\right\}+[K]\{\mathrm{u}\}=\{0\}
$$

$$
\left([K]-\omega^{2}[M]\right)\{\mathbf{u}\}=\{0\}
$$

Equ. 3 is a set of $\mathrm{N}$-ary linear homogeneous algebraic equations and the necessary and sufficient condition of the equation group having a none zero solution is that its coefficient equation determinant equals zero. That is 


$$
\Delta\left(\begin{array}{c}
- \\
\omega^{2}
\end{array}\right)=\left|K_{\mathrm{ij}}-\bar{\omega}^{2} \mathrm{~m}_{\mathrm{ij}}\right|=0
$$

The determinant (4) is called the characteristic determinant, and the $\mathrm{N}$-algebraic equations can be obtained by expanding it.

$$
\omega^{-2 \mathrm{n}}+\alpha_{1} \omega^{2(\mathrm{n}-1)}+\alpha_{2} \omega^{2(\mathrm{n}-2)}+\cdots+\alpha_{n-1} \omega^{2}+\alpha_{n}=0
$$

It is assumed that the mass matrix and stiffness matrix of the system are positive definite real symmetric matrices. Mathematically it can be proved that the n roots of equation (5) are positive real roots which correspond to $n$ natural frequencies of the system. Assuming there is no heavy root, it can be sorted from small to large sequentially:

$$
\omega_{1}^{2}<\omega_{2}^{2}<\omega_{3}^{2}<\cdots<\omega_{n}^{2}
$$

\section{The Establishment of the Geometrical Model of the Main Frame}

\subsection{Inverter Cabinet Introduction}

The inverter cabinet is composed of six parts as shown in Figure 1, they are power input part, control part, capacitor part, half bridge power unit part, power output part and water-cooled system part. For the vibration studying of inverter cabinet, the main frame plays the role of bearing, so the main frame structure and the force transfer between the damping system are mainly studied in modeling. Other components such as shielding, installation operations, seals and other connections are not load-bearing. When establishing vibration simulation model of inverter, the main frame of inverter should be retained and others such as enclosures, mounting hangers and electromagnetic shielding components need to be removed from the model. In order to ensure that the frame design has sufficient safety reserve, this paper mainly analyzes the bearing structure components of the main frame.

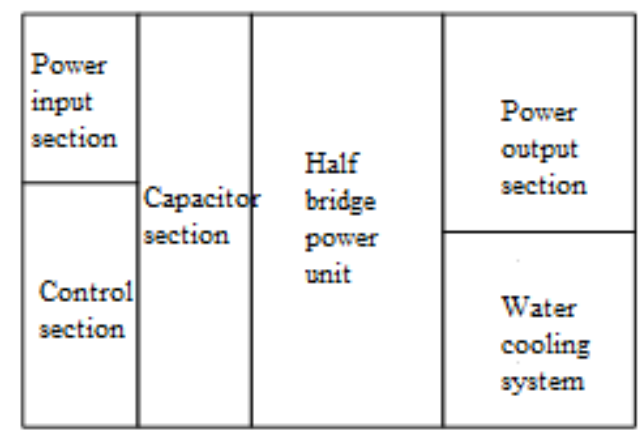

Figure 1. Schematic Diagram of Inverter Cabinet

The whole inverter model is established in the ANSYS software. Before the model of inverter is calculated, the direction of the model should be set. The portrait of the frame is set to the $\mathrm{X}$ axis, the horizontally of frame is set to the $\mathrm{Y}$ axis and the vertical direction of the frame is set to $\mathrm{Z}$ axis. The beam element is distributed in the frame structure. In general, we analyze the stress of the frame beam element of the cabinet body. It needs to model the shell element or three-dimensional entity element. Because the three-dimensional entity element modeling can be better equivalent to the actual object's quality and improve the calculation precision, so the main frame finite element model is established by three-dimensional entity element.

\subsection{Finite Element Mesh Division}

Grid partitioning is an important part of finite element analysis, and the quality of grid determines the precision of the calculation result and the size of the calculation scale. Therefore, in the pretreatment analysis, the inverter cabinet should be reasonably divided into grids[2, 3]. When determining the number of grids, the type of profiling data should be considered. 
In the static structure analysis of the inverter, the number of grids can be less if only the deformation of the calculation structure is calculated. If the stress needs to be calculated, a relatively large number of meshes should be obtained when the accuracy requirements are the same[4]. In response calculation, the mesh number of the calculated stress response is more than the calculated displacement response. Grid density refers to the use of different sizes of grids in different parts of the structure which is to adapt to the distribution of computational data. In order to reflect the rule of data change better, it is necessary to use the dense grid in the area where the gradient of the data variation is large such as stress concentration. In the area where the gradient of data variation is small, the grid is sparse[5].

In order to ensure that the model has enough density, the finite element model is divided into several meshes with the actual calculation ability, and the mesh refinement is done for the part concerned. Finally, the grid of the model is determined by analyzing the convergence of the grid iteration. The division of the finite element mesh of the main frame is shown in Figure 2.

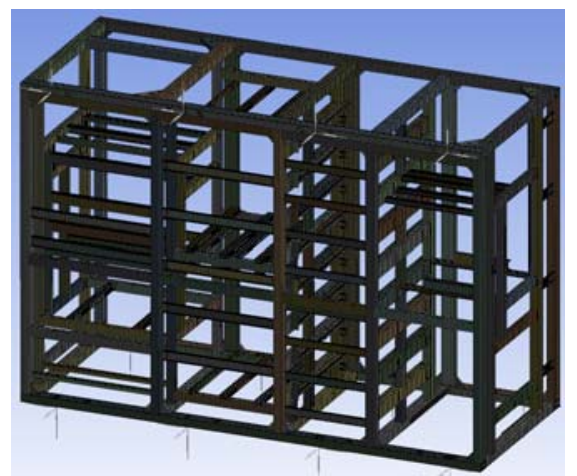

Fig. 2. The Finite Element Mesh of the Main Frame

\subsection{Spring Damping Connection Setting}

The simulation uses the spring damping element to simulate as the shock absorber. Each damper is provided with three connecting units which can be used to simulate the stiffness and damping characteristics in three directions ( $\mathrm{X}, \mathrm{Y}$ and $\mathrm{Z}$ ). When modeling, each connection unit is set to common node on the main frame and the other three nodes are fixed to the installation backplane. In the inverter model, there are 36 spring units need to be established, and their dynamic stiffness setting are required to vibration analysis.

\section{The Establishment of the Geometrical Model of the Main Frame}

\subsection{Vibration Working Condition Analysis}

Modal analysis is based on the frequency section of the search calculation. In the modal analysis of the inverter, the specified 40-order mode are analyzed which range from 0 to $120 \mathrm{~Hz}$. Generally, the former modal order is needed to pay more attention because the lower the frequency, the easier it is to produce the corresponding vibration. Calculated results of modal order of the inverter is shown in table 1.

Table 1. Modal Order and the Frequency Value

\begin{tabular}{cc||cc||cc||cc}
\hline Mode & Frequency $[\mathrm{Hz}]$ & Mode & Frequency $[\mathrm{Hz}]$ & Mode & Frequency $[\mathrm{Hz}]$ & Mode & Frequency [Hz] \\
\hline 1 & 5.48 & 11 & 49.76 & 21 & 64.49 & 31 & 74.56 \\
2 & 6.46 & 12 & 51.69 & 22 & 64.93 & 32 & 75.57 \\
3 & 8.10 & 13 & 52.36 & 23 & 65.39 & 33 & 76.92 \\
4 & 11.71 & 14 & 55.05 & 24 & 65.79 & 34 & 80.56 \\
5 & 15.47 & 15 & 61.16 & 25 & 66.60 & 35 & 81.36 \\
6 & 15.59 & 16 & 62.64 & 26 & 69.68 & 36 & 81.98 \\
7 & 36.99 & 17 & 62.70 & 27 & 70.03 & 37 & 83.63 \\
8 & 38.01 & 18 & 63.67 & 28 & 71.11 & 38 & 83.79 \\
9 & 45.32 & 19 & 64.31 & 29 & 71.56 & 39 & 84.31 \\
10 & 47.81 & 20 & 64.41 & 30 & 72.88 & 40 & 84.85 \\
\hline
\end{tabular}


From table 1, we can see that the first-order modal frequency is $5.48 \mathrm{~Hz}$ and the first six-order modal value is not more than $16 \mathrm{~Hz}$.

\subsection{Harmonic Response Analysis}

According to the table C.9 in Appendix C of GJB150.16a-2009 (Table 2), the vibration calculation is performed according to 1 to $16 \mathrm{~Hz}$, and the displacement amplitude is $1 \mathrm{~mm}$. When 16 to $60 \mathrm{~Hz}$, the acceleration amplitude is taken as $10 \mathrm{~m} / \mathrm{s}^{2}$ for frequency division calculation.

Based on Table 2, the vibrations in the $\mathrm{X}, \mathrm{Y}$ and $\mathrm{Z}$ three directions are computed in two cases. In one case, the calculation frequency range is from $1 \mathrm{~Hz}$ to $16 \mathrm{~Hz}$ and the frequency interval is set to $1 \mathrm{~Hz}$. In the other case, the calculation frequency range is from $16 \mathrm{~Hz}$ to $60 \mathrm{~Hz}$ and the frequency interval is set to $1 \mathrm{~Hz}$. The total vibration calculation steps of each direction are 60 . This will get two results in $16 \mathrm{~Hz}$ and the lager value will be adopted.

Table 2. GJB150.16a-2009 Table C.9

\begin{tabular}{|c|c|c|c|c|}
\hline \multirow[b]{2}{*}{ Classification } & \multirow[b]{2}{*}{ Partition } & \multicolumn{3}{|c|}{ Test parameters } \\
\hline & & $\begin{array}{c}\text { Frequency } \\
\mathrm{Hz}\end{array}$ & $\begin{array}{c}\text { Displacement } \\
\mathrm{mm}\end{array}$ & $\begin{array}{c}\text { Acceleration } \\
\mathrm{m} / \mathrm{s}^{2}\end{array}$ \\
\hline Surface ship and submarine & \multirow{2}{*}{ Main area } & $\begin{array}{c}1 \sim 16 \\
16 \sim 60\end{array}$ & 1.0 & 10 \\
\hline High speed diesel and speedboat & & $\begin{array}{c}10 \sim 35 \\
35 \sim 160 \\
\end{array}$ & 0.5 & 25 \\
\hline \multirow[t]{2}{*}{ Various types of ships } & \multirow[t]{2}{*}{ Mast area } & $\begin{array}{c}2 \sim 10 \\
10 \sim 16 \\
16 \sim 50 \\
\end{array}$ & $\begin{array}{l}2.5 \\
1.0\end{array}$ & 10 \\
\hline & & $\begin{array}{c}2 \sim 25 \\
25 \sim 100\end{array}$ & 1.6 & 40 \\
\hline
\end{tabular}

In the harmonic response analysis, the direction load excitation is applied in the $\mathrm{X}, \mathrm{Y}$ and $\mathrm{Z}$ direction respectively. The load excitation is the foundation load excitation which is applied to the constraint position[7]. In the analysis of the inverter, there is no direct restriction of freedom. When the actual model is conversed to the finite element model, there is a node on the spring grounding which has a full freedom constraint. Therefore, in the harmonic response analysis, the direction acceleration and displacement excitation are applied to all spring grounding nodes and two harmonic response analysis are calculated in each direction.

In order to obtain the curve of maximum equivalent stress corresponding to frequency, it is necessary to extract the equivalent stress value by APDL, and the curves can be obtained in $\mathrm{X}, \mathrm{Y}$ and $\mathrm{Z}$ direction which are shown in Fig. 3, Fig.4, and Fig.5.

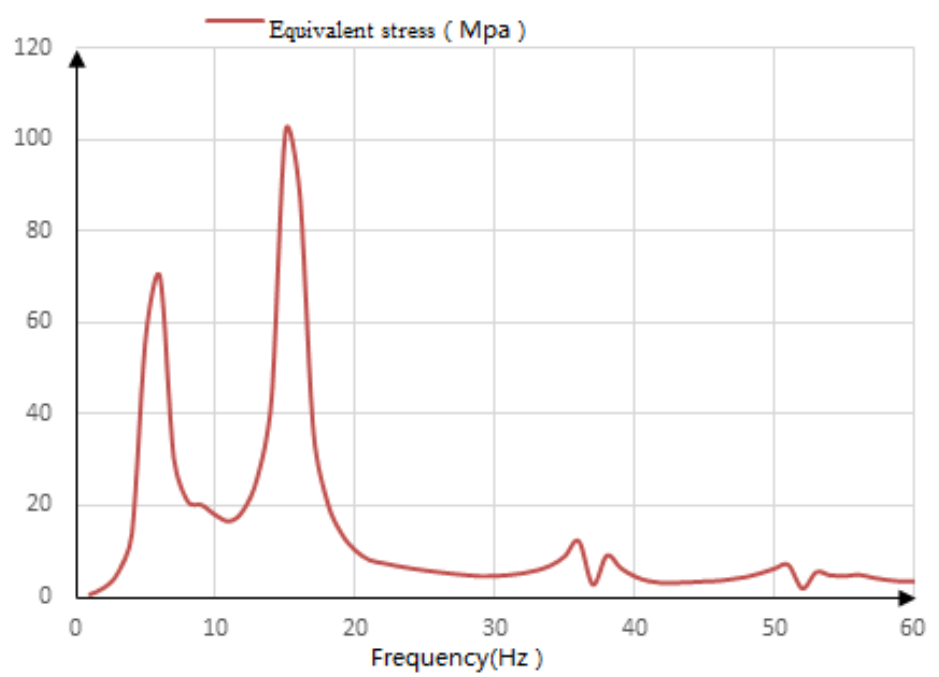

Figure 3. Curve of Equivalent Stress Amplitude in X Direction Corresponding to Frequency 


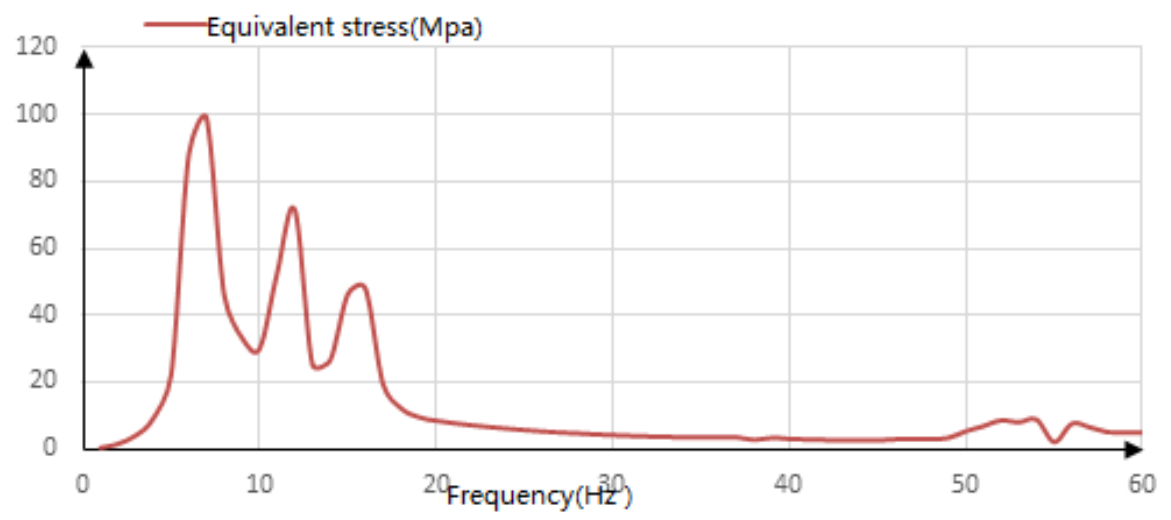

Figure 4. The Curve of Equivalent Stress Amplitude in Y Direction Corresponding to Frequency

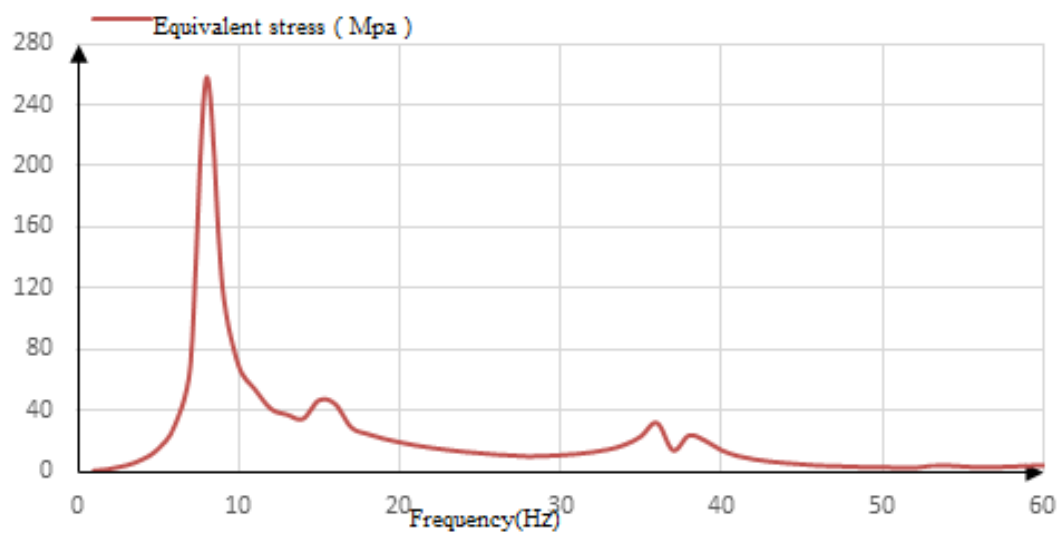

Figure 5. The Curve of Equivalent Stress Amplitude in Z Direction Corresponding to Frequency

From the result curve in Fig. 3, the maximum equal effect force is $101.8 \mathrm{MPa}$ at $15 \mathrm{~Hz}$. From the result curve in Fig.4, the maximum equal effect force is 99.0MPa at 7Hz.From the result curve in Fig. 5 , the maximum equal effect force is $257.8 \mathrm{MPa}$ at $8 \mathrm{~Hz}$ time. The overall stress level of the main frame structure is lower. The place where the vibration is the most value is the low order frequency, the frequency is in the first 6-order frequency range, which shows that the lower-order frequency has greater influence on the structure itself than the higher-order frequency, the lower the frequency, the more easily the vibration phenomenon occurs. Table 3 shows the calculation results of vibration analysis.

Table 3. Calculation Results of Vibration Analysis

\begin{tabular}{ccc}
\hline \hline & \multicolumn{2}{c}{ Equivalent stress } \\
\cline { 2 - 3 } Direction & $\begin{array}{c}\text { Maximum Value } \\
(\mathrm{mm})\end{array}$ & $\begin{array}{c}\text { Frequency of Occurrence } \\
(\mathrm{Hz})\end{array}$ \\
\hline $\mathrm{X}$ 向 & 101.8 & 15 \\
$\mathrm{Y}$ 向 & 99.0 & 7 \\
$\mathrm{Z}$ 向 & 257.8 & 8 \\
\hline \hline
\end{tabular}

\section{Conclusion}

In this paper, a mechanical model of the main frame of the inverter is established. According to the basic theory of finite element analysis, the load-bearing component of the inverter frame is analyzed. Firstly, the main frame is divided into mesh grids. In the finite element model, the longitudinal, transverse and vertical of the main frame are set to $\mathrm{X}, \mathrm{Y}$ and $\mathrm{Z}$ axis respectively. Then the modal analysis of the whole structure is analyzed and the results of the stress calculation of the main frame structure in vibration are obtained. The results show that the overall stress level is within the allowable range of the material strength under the vibration condition of the cabinet frame. The whole structure of the frame is designed rationally. 


\section{References}

[1]. Linfeng Cheng, Minyi Wang, Chaoxue Huang. Research on Vibration Reliability of Shipborne Electronic Cabinet Based on ANSYS [J]. Journal of Sichuan Ordnance Industry, 2014, 35(01): 115-118.

[2]. Zengguang Li. Calculation and Analysis of Vibration Isolation Performance of Floating Raft and Double-layer Vibration Isolation Device [J].Noise and Vibration Control, 2015, 35(06):65-68.

[3]. Linfeng Cheng. Vibration Analysis and Vibration Reduction Strategy of Ship Control Cabinet [D]. China Ship Research Institute, 2014.

[4]. Zhongdong Wan\& Suhuan Chan .Sensitivity analysis of eigenmodes and dynamic responses for intelligent structures [J] • Finite Elements in Analysis and Design. 1999(33):71-81.

[5]. Wang Wei,Cheng Linfeng. Study on Random Vibration Simulation of a Military Electronic Cabinet [J]. Electronic world, 2014(09):119.

[6]. GJB 150.16A-2009 Environmental testing methods for military equipment - Part 16: Vibration test

[7]. Mingwen $\mathrm{Xu}$, Hui Liu. Vibration Analysis of Electronic Equipment Cabinet [J].Journal of Beijing University of Posts and Telecommunications, 1984(02):107-113. 